\title{
Peculiarities of distribution of anthropogenic radionuclides in soils and soil fractions of conjugated floodplain landscapes of the Yenisey River
}

\author{
A.G. Volosov ${ }^{1}$, V.G. Linnik ${ }^{1}$, E.M. Korobova ${ }^{1}$, V.V. Krupskaya ${ }^{2}$ and J.E. Brown ${ }^{3}$ \\ ${ }^{1}$ Vernadsky Institute of Geochemistry and Analytical Chemistry, Kosygin Street 19, 117975 \\ Moscow, Russia \\ ${ }^{2}$ Institute of Geology of Ore Deposits, Petrography, Mineralogy, and Geochemistry, \\ Russian Academy of Sciences, Staromonetny Per., 35, Moscow 119017, Russia \\ ${ }^{3}$ Norwegian Radiation Protection Authority, P.O. Box 55, N-1332 Østeras, Norway
}

\section{INTRODUCTION}

The Yenisey River belongs to one of the main Siberian water systems flowing into the Arctic basin. Technogenic radionuclides have entered this system due to activities at the Krasnoyarsk Mining and Chemical Combine (KMCC), situated approximately $40 \mathrm{~km}$ downstream from the city of Krasnoyarsk (Zheleznogorsk), which began operations in August of 1958 (start-up of the first straight-through reactor, a second reactor was operated from 1961). In the period of 1958 to 1992 the river channel and flood plain were exposed to contamination at great distances downstream from the waste discharge point. Various long-lived radionuclides were measured in the environment such as ${ }^{137} \mathrm{Cs},{ }^{60} \mathrm{Co},{ }^{152} \mathrm{Eu},{ }^{154} \mathrm{Eu}$ with half-lives of 30.2, 5.3, 13.3 and 8.6 years correspondingly. Both reactors were decommissioned in 1992 and since then radionuclide discharges to the river have decreased by several tens of times.

The first information about the considerable radionuclide contamination of the Yenisey River for a reach extending to approximately $2000 \mathrm{~km}$ downstream of Krasnoyarsk and detected up to the entry of the river into the Arctic basin was obtained in the early 1970-ies [1] but these data were not available for the wider scientific community.

Detailed radioecological studies of the Yenisey contamination started in the 1990-ies. The purpose of this study, performed within two international projects STREAM and ESTABLISH, was to investigate patterns of and environmental factors affecting the distribution of anthropogenic radionuclides in flood plain landscapes of the Yenisey River at different distances from the discharge point of the Krasnoyarsk Mining and Chemical Combine down to the estuarine zone. The study area included islands in the mid reaches of the Yenisey River and locations within the estuary. A variable pattern of distribution and local accumulation of long-lived radionuclides in floodplain landscapes was observed that appeared to be strongly dependent upon landscape- and hydrological factors.

\section{METHODS}

Soil cores were obtained at sites representative of different distances from the KMCC discharge area during field campaigns conducted in 1999, 2000 and 2002.

Radionuclides activity concentrations were determined in the collected samples after drying using a "Canberra" gamma-spectrometer. Exposition of the soil samples and selected fractions varied from 40 to 180 minutes. The error of determination did not exceed $7 \%$ for ${ }^{137} \mathrm{Cs}$ and reached $60 \%$ in a few cases for ${ }^{60} \mathrm{Co},{ }^{152,154} \mathrm{Eu}$. Some specimens of low weight (about 20-30 g) were measured by a HP-Ge 
detector of the Baltic Scientific Instruments (BSI), type GCD-20190 using a SBS-55 GreenStar (Russia) spectrometer. All results are decay corrected to the sampling date.

Granulometric composition of the flood plain soils was determined by a complex technique. The initial sample of approximately $30 \mathrm{~g}$ was subjected to a two minute ultrasonic treatment and washed with distilled water (to escape the loss of radionulcides) through a $0.05 \mathrm{~mm}$ sieve. Fractions larger than $0.05 \mathrm{~mm}$ were dry sieved while smaller fractions were separated by sedimentation technique and sampled by pipette in time intervals to obtain fractions sized $0.01-0.005 \mathrm{~mm} ; 0.005-0.001 \mathrm{~mm}$, and $<0.001 \mathrm{~mm}$. After that the siltstone fraction of $0.05-0.01 \mathrm{~mm}$ was washed of the smaller particles, collected and dried. After determination of masses of all the fractions their portions were calculated in percent of the total dry sample mass. Mineralogical composition was carried out with the help of XRD D/MAX 2200 RUGAKU, Japan, by V. Krupskaya (IGEM RAS).

\section{RESULTS AND DISCUSSION}

Radioactive contamination in vicinity of the discharge point is characterized by high variation [2-4]. For example, the coefficient of variation $(\mathrm{CV})$ for ${ }^{60} \mathrm{Co}$ and ${ }^{152,154} \mathrm{Eu}$ (according to field radiometric survey, STREAM data) at a distance of 16-20 km from the KMCC equaled 78-107\% and 60-127\% respectively. Absolute values of the ${ }^{60} \mathrm{Co},{ }^{152,154} \mathrm{Eu}$ contamination density reached $98-188 \mathrm{kBq} / \mathrm{m}^{2}$ and at a number of sampling points equalled those of ${ }^{137} \mathrm{Cs}$ (maximum $\left.=250-1000 \mathrm{kBq} / \mathrm{m}^{2}\right)$. At a distance of $250 \mathrm{~km}$ from the $\mathrm{MCC}{ }^{60} \mathrm{Co},{ }^{152,154} \mathrm{Eu}$ contamination levels fell by a factor of 10 while levels of ${ }^{137} \mathrm{Cs}$ decreased by no more than 2.4 times. Variation in the contamination density in the remote zone was still considerable and the $\mathrm{CV}$ equaled $93 \%$ for ${ }^{60} \mathrm{Co},{ }^{152,154} \mathrm{Eu}$ and $133 \%$ for ${ }^{137} \mathrm{Cs}$.

Twenty kilometers away from the $\mathrm{KMCC},{ }^{60} \mathrm{Co}$ activity concentrations in the upper layers of soil $(0-3 \mathrm{~cm})$ was $140-220 \mathrm{~Bq} / \mathrm{kg}$. Traces of ${ }^{60} \mathrm{Co}(2-2.5 \mathrm{~Bq} / \mathrm{kg})$ were found at a depth of $25-30 \mathrm{~cm}$. Contamination of the same soil upper horizons by ${ }^{152} \mathrm{Eu},{ }^{154} \mathrm{Eu},{ }^{155} \mathrm{Eu}$ equaled to $800,160,30 \mathrm{~Bq} / \mathrm{kg}$ respectively. In specific cases maximum depth of ${ }^{152} \mathrm{Eu}$ detection $(21 \mathrm{~Bq} / \mathrm{kg})$ reached $30-35 \mathrm{~cm}$.

Cs-137 activity in the soil profiles in the middle reaches of the Yenisey River were in the range $23-3770 \mathrm{~Bq} / \mathrm{kg}$ (dry weight), local radionuclide contamination was found as far downstream as the Island of Tungussky. At a distance of $250 \mathrm{~km}$ from the $\mathrm{MCC}$ an insignificant ${ }^{155} \mathrm{Eu}$ concentration $(8 \mathrm{~Bq} / \mathrm{kg})$ was registered in one case in the top layer $0-2 \mathrm{~cm}$. As far as the island of Ust'-Tungussky ( $250 \mathrm{~km}$ downstream from the KMCC) an insignificant amount of ${ }^{155} \mathrm{Eu}(8 \mathrm{~Bq} / \mathrm{kg}$ ) was found in an individual case in the top 2-cm layer. This radioisotope was accompanied by ${ }^{152} \mathrm{Eu},{ }^{154} \mathrm{Eu}$ contamination $(8 \mathrm{~Bq} / \mathrm{kg}$ and $4 \mathrm{~Bq} / \mathrm{kg}$ correspondingly) which was detected to a depth of $10 \mathrm{~cm}$.

In the Yenisey Estuary and delta zones, the major part of the total activity of radionuclides (76\%$95 \%$ ) in soil layers was due to the contribution from ${ }^{40} \mathrm{~K}$, a minor portion (2 to $5 \%$ ) due to ${ }^{226} \mathrm{Ra}$ and ${ }^{232} \mathrm{Th}$, respectively. The fraction of ${ }^{137} \mathrm{Cs}$ estimated was less than $1 \%$ of the total activity on average. However, this level increased in study sites located in the accumulative floodplain and terrace landscapes: up to $8.5 \%$ and $14.9 \%$ respectively.

The contaminated flood plain cores characterized by accumulation of silt and clay river deposits exhibited sub-surface maxima of ${ }^{137} \mathrm{Cs}$ and confirmed the distant migration and burial of this radionuclide. Local maximum ${ }^{137} \mathrm{Cs}$ contamination significantly exceeding global estimates were found for soil cores sampled on the islands of Tysyara formed in the middle part of the delta (up to $24.7 \mathrm{kBq} / \mathrm{m}^{2}$ ) and on Pashkov Island in the upside delta in the vicinity of set. Ust'Port (about $88 \mathrm{kBq} / \mathrm{m}^{2}$ [5] due to ${ }^{137} \mathrm{Cs}$ accumulation in a silty layer $15-20 \mathrm{~cm}$ deep, $\sim 600 \mathrm{~Bq} / \mathrm{kg}$. Contamination densities at the other plots did not exceed $5.3-6.1 \mathrm{kBq} / \mathrm{m}^{2}$. The median values of $1.1 \mathrm{kBq} / \mathrm{m}^{2}$ for the sites sampled in the gulf and delta area and $2.8 \mathrm{kBq} / \mathrm{m}^{2}$ for the upside delta sites were within or close to the global fallout range. Traces of ${ }^{60} \mathrm{Co}$ radionuclide $(1.6-8.4 \mathrm{~Bq} / \mathrm{kg})$ were detected only in two Pashkov floodplain cores. Concentration peaks for ${ }^{60} \mathrm{Co}$ corresponded to a depth of $10-15$ and $15-20 \mathrm{~cm}$ that correlated with the ${ }^{137} \mathrm{Cs}$ increase in these profiles. This supports the hypothesis of MCC radioactive trace in the Yenisey delta zone and the accumulative role of the Yenisey's upper delta section. 


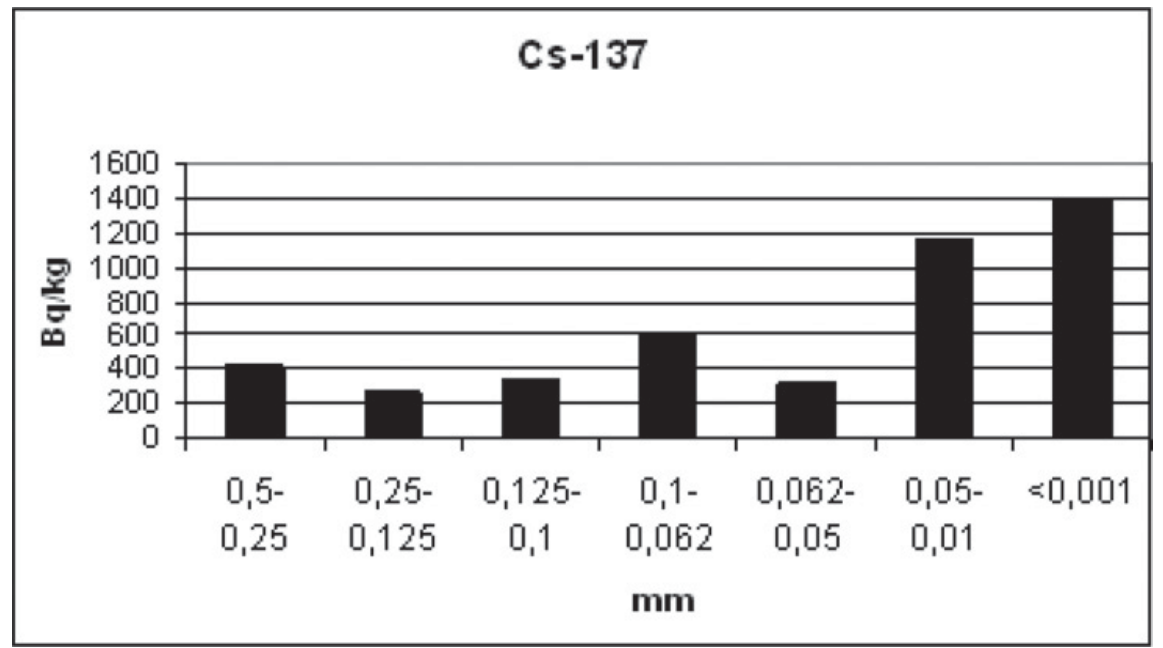

Figure 1. Distribution of ${ }^{137} \mathrm{Cs}$ in soil fractions of different size in vicinity of the MCC.

\subsection{Cs-137 accumulation in soil granulometric fractions}

Analysis of ${ }^{137} \mathrm{Cs}$ distribution in granulometric fractions of the soil samples collected in vicinity of the KMCC showed that the radioisotope accumulated mainly in fine particles. Nevertheless, larger particles $\left(0.5-0.25 \mathrm{~mm}\right.$ in diameter) contained approximately $400 \mathrm{~Bq} / \mathrm{kg}$ of ${ }^{137} \mathrm{Cs}$, and in the period of high water such particles, which can be carried in suspension, had transported a considerable part of the radioactivity. However, the fine fraction (less than $0.001 \mathrm{~mm}$ ) was the main ${ }^{137} \mathrm{Cs}$ carrier over long distances.

In the lower Yenisey, ${ }^{137} \mathrm{Cs}$ in particles of different sizes were determined in the most contaminated four soil profiles sampled at Tysyara and Pashkov islands which characterized the medium and low floodplain levels. Maximum ${ }^{137} \mathrm{Cs}$ contamination was found in the lower silty and clay horizons of the profile PSH1-3 situated on the back slope of the low ridge at the head of Pashkov Island. This area represented the first sedimentation zone (barrier) on the route for suspended particles transported by the river to the estuary. The silt and clay content in the layer $30-35 \mathrm{~cm}$ deep exceeded $98 \%$.

\subsection{Soil mineralogy and radionuclide contamination}

Mineralogical analysis of the sediments deposited in the middle reaches of the Yenisey River showed that they are composed mainly of quartz, K-feldspar and plagioclase. The latter dominated and made up $48-57.7 \%$ of the samples. The quartz content in the top $0-10 \mathrm{~cm}$ layer varied from 13.7 to $18.8 \%$ at almost all the plots. Micas were characterised by black species and muscovite occurs in particular cases. Among accessory minerals, zircon and magnetite were determined. Clay minerals belonged to illite-chlorite association with admixtures of smectite and kaolinite.

In the lower Yenisei reaches the particular samples from the soil profiles analyzed for particle size were studied also for mineralogical composition [6]. The very fine sand fraction $(0.063-0.05 \mathrm{~mm})$ mainly consisted of feldspars (albite and microcline) and quartz. The contribution of these minerals to finer fractions $(<0.01 \mathrm{~mm})$ was also considerable $(20-45 \%)$. The portion of clay minerals in fractions $<0.01 \mathrm{~mm}$ varied from $40 \%$ to $72 \%$. A considerable contribution of clay minerals was found in fractions sized in the range $10-5 \mu \mathrm{m}$. Therefore, clay minerals can be transported by the river associated with the fine silt fraction and fine silt particles can have high sorption properties due to the presence of clay minerals. XRD analysis showed that clay minerals were composed mainly of smectite and hydromica 


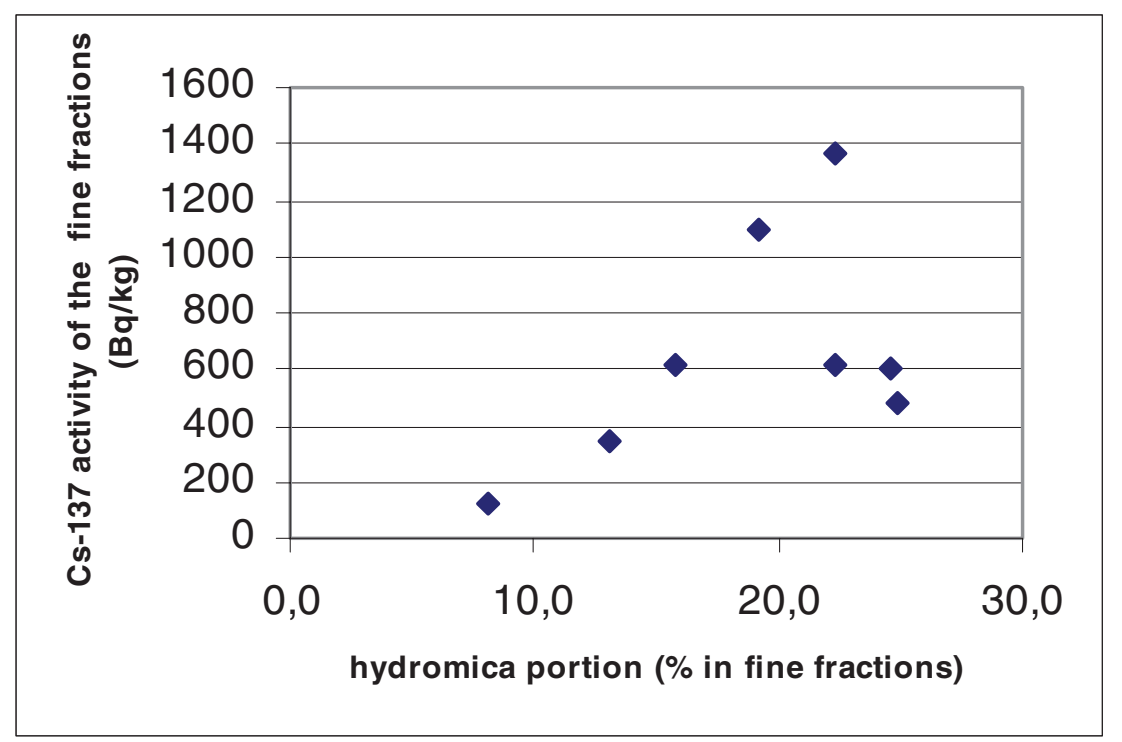

Figure 2. Relation of Cs-137 content in fine fractions with the contribution of illite in the lower Yenisey soil layers.

almost in equal amounts (7-33\% and 8-25\% respectively), and chlorite (5-18\%). Kaolinite did not exceed $3-8 \%$. The clay assemblages suggest a high sorption capacity for $\mathrm{Cs}^{+}$in the analyzed sediments.

The Cs-137 concentration was related to the portion of illite (hydromica) in the corresponding fraction (Fig. 2). The finest fractions $(<0.001 \mathrm{~mm})$ contained lower amounts of Cs-137 despite the higher abundance of hydromica and smectite. In our opinion this can be explained by Cs-137 migration with coarser (silt) sediments enriched in hydromica during periods of flooding. The significance of hydromica in ${ }^{137} \mathrm{Cs}$ fixation in alluvium was shown for the Iput flood plain contaminated after the Chernobyl accident [7].

\section{CONCLUSIONS}

Analysis of different granulometric fractions and their radionuclide balance showed that ${ }^{137} \mathrm{Cs}$ accumulated in soil layers of different grain size including small-grained and fine sands while ${ }^{152} \mathrm{Eu}$, ${ }^{154} \mathrm{Eu}$ and ${ }^{60} \mathrm{Co}$ were incorporated particularly in silty and clay layers. This probably reflected a distant ${ }^{137} \mathrm{Cs}$ water migration and secondary sorption in contrast to ${ }^{152} \mathrm{Eu},{ }^{154} \mathrm{Eu}$ and ${ }^{60} \mathrm{Co}$ for which the activity concentrations appeared to be significantly correlated with the $<0.01 \mathrm{~mm}$ fraction. Therefore, the suggestion is that these radionuclides have been carried and deposited mainly with fine particles. Mineralogical analysis of the selected soil samples showed that in the presence of abundant amorphous $\mathrm{SiO}_{2}$, the sorption of caesium is related to illite. In other cases, the distribution of ${ }^{137} \mathrm{Cs}$ may be controlled by chlorite or smectite (and mixed-layer minerals) ratios in different clay fractions.

\section{References}

[1] Vakulovsky S.M., Kryshev I.I., Nikitin A.I., Savitsky Yu.V., Malyshev S.V., Tertyshnik E.G., J. Env. Rad. 29 (1995) 225-236.

[2] Linnik V.G., Brown J.E., Dowdall M ., Potapov V.N., Surkov V.V., Korobova E. M., Volosov A.G., Vakulovsky, S.M., Tertyshnik, E.G., Science of the Total Environment 339 (2005) 233-251.

[3] Linnik, V.G., Brown, J.E., Dowdall, M., Potapov, V.N., Nosov, A.V., Surkov, V.V., Sokolov, A.V., Wright, S.M. and Borghuis, S., J. Env. Rad. 87 (2006) 188-208. 
[4] Standring, W. J. F., Brown, J. E., Dowdall, M., Korobova, E. M., Linnik, V. G., Volosov, A. G., J. Env. Rad. 100 (2009) 1109-1120.

[5] Korobova, E. M., Brown, J., Ukraintseva, N. G., Surkov V. V. (2007). J. Env. Rad. 96 (2007) 144-156.

[6] Korobova E.M., Ukraintseva N.G., Surkov V.V., Brown J.E., Standring, W. Borisov, A.P., Radionuclide Distribution in the Lower Yenisey and Pechora Reaches: Landscape geochemical Signatures and Patterns in Global and Regional Contamination. River Pollution Research Progress. Eds: Mattia N. Gallo, Marco N. Ferrari. Nova Science Publishers, Inc. N-Y, 2009, pp. 91-156.

[7] Korobova, E. M., Chizhikova, N. P., Eurasian Soil Science 40 (2007) 1062-1075. 